\title{
Qualification of an Epoxy Resin System for Use in Secondarily Formable CFRP Rebars
}

\author{
Michael Müller-Pabel, Daniel Wohlfahrt, Sirko Geller and Maik Gude
}

Michael Müller-Pabel. Technische Universität Dresden - Institute of Lightweight Engineering and Polymer Technology

Holbeinstr. 3, D-01307 Dresden, Germany

Daniel Wohlfahrt. Technische Universität Dresden - Institute of Lightweight Engineering and Polymer Technology Holbeinstr. 3, D-01307 Dresden, Germany

Corresponding author: Wohlfahrt, Daniel. E-mail address: daniel.wohlfahrt@tu-dresden.de

Sirko Geller. Technische Universität Dresden - Institute of Lightweight Engineering and Polymer Technology Holbeinstr. 3,

D-01307 Dresden, Germany

Maik Gude. Technische Universität Dresden - Institute of Lightweight Engineering and Polymer Technology Holbeinstr. 3, D-01307 Dresden, Germany

\begin{abstract}
The use of reinforcing bars has been known for more than 150 years in construction sector, in order to compensate the limited tensile strength of concrete. Steel is the most widespread and standardized rebar material. As industry targets a reduction of resource consumption and increased freedom of design, novel materials come into the scope of current research efforts. In this context, carbon fiber reinforced polymers (CFRP) have become a promising candidate for rebar materials as they offer excellent corrosion resistance and mechanical properties. Their use enables significant reduction of concrete cover in future buildings and costefficient maintenance of bridges. The resin system used for manufacturing of CFRP rebars dictates possible applications. Thermoplastic polymers offer the advantage of formability in a molten state. On the other hand, they provide limited heat and fire resistance, what hinders further industrialization. In contrast, thermosets deliver high mechanical and thermal properties due to their polymeric network structure. This is also the reason for their restricted formability after gelation has occurred. However, it is known that epoxy resins may sustain substantial plastic deformation when being deformed at elevated temperatures and in a partial cure state. In this work, a commercially available resin system is selected and qualified for potential use in thermoset-based CFRP rebars. Based on the resin characterization comprising reaction kinetics as well as tensile and compressive tests at partial cure, general guidelines and limits for secondary forming are derived. The feasibility is demonstrated by bending tests on CFRP stripes with varied fiber orientation.
\end{abstract}

Keywords. Fiber Reinforced Rebars, Plasticity, Thermoset

\section{Introduction}

The reinforcement of concrete with rebars enables substantial increase of design freedom, resource-efficiency and safety. As can be seen in the example of Fig. 1 thin-walled and elegant buildings can be realized by reinforced shell constructions. Regarding design of such structures, secondary forming of the reinforcing elements is a widely used method to provide the required stirrups, angles or individually curved segments. Forming operations are comparatively simple to realize if conventional isotropic metallic materials are used. On the other hand, these involve the risk of corrosion and consequently a need for frequent inspections or restauration.

In order to overcome these problems and to enhance the lightweight potential of future buildings, novel reinforcing materials are being developed. In this context, rebars made of fiber-reinforced polymers (FRP) allow substantial improvement along the whole life-cycle [1]. To meet high requirements in terms of heat-resistance and mechanical properties, especially thermoset matrix materials are of interest. As thermosets form a molecular network during manufacturing, they are often classified as non-formable. In contrast, thermoplastic matrix materials can be repeatedly molten and re-shaped at elevated temperatures in order to generate global or local functionalities [2]. Hence, curved thermoset FRP rebars are currently manufactured by using individual molding tools or adapted technologies like 
radius pultrusion resulting in fixed curvatures and radii [3]. Hence, only straight profiles or readily formed rebars with pre-defined shape are commercially available [4]. However, in dependence on composition and temperature [5,6] thermosets may allow a notable degree of plasticity, which is often neglected or unknown. A distinctive brittle-ductile transition can be observed in the vicinity of glass transition temperature [7-9]. Under this premise, it is suggested to makes use of the plastic deformation potential of thermoset matrix materials in order to gain a substantial increase in flexibility, cost-efficiency and lightweight potential of future FRP reinforced concrete structures.

An experimental program was performed using a commercially available fast-curing epoxy resin system. A reaction kinetic model is calibrated according to DSC data and subsequently employed to define adapted cure cycles that result in partial cure states. Quasi-static tests in tensile and compression mode were conducted at elevated temperatures using partially cured neat resin specimens. General guidelines for forming are derived and transferred to bending experiments on carbon fiber-reinforced polymer (CFRP) specimens that were manufactured from the same epoxy resin. Instead of pultruded rebars, composite stripes were cut from molded plate material in order to rely on a simplified manufacturing method that enables a trouble-free variation of fiber orientations, fiber volume content and degree of cure.

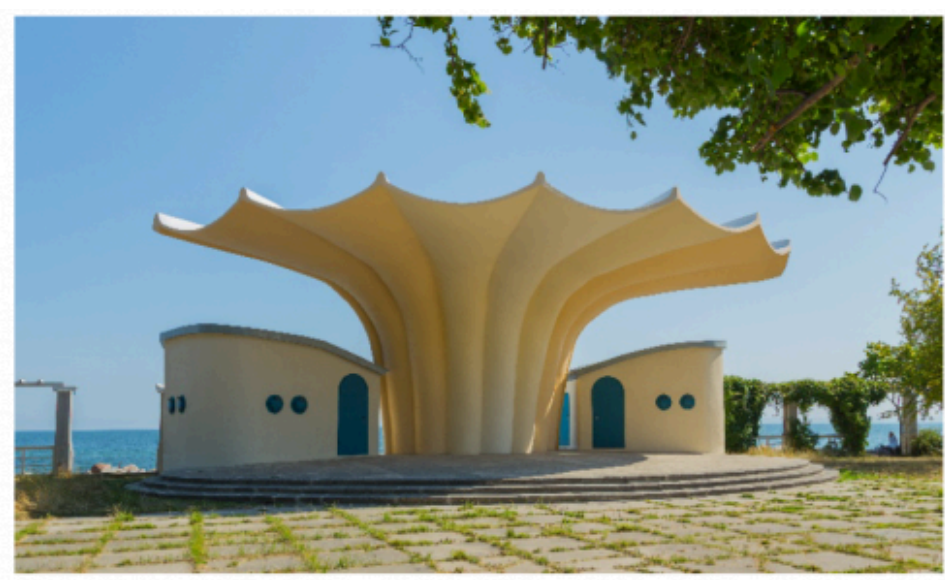

Fig. 1. "Kurmuschel” in Sassnitz (Germany) based on a shell construction with conventional steel rebars (picture by J.-H. Janßen, CC BY-SA 4.0)

\section{Materials and Methods}

\subsection{Material Selection and Pre-Cure}

Commercially available resin XB6469 resin and Aradur 2954 hardener supplied by Huntsman International LLC were selected. The components are mixed to a ratio of 100:42 pbw and degassed prior to testing and manufacturing. Neat resin was used for DSC scans in order to generate input data for reaction kinetic modelling. Partially cured resin material was used to determine the dependence of the glass transition on degree of cure (DOC).

Furthermore, solid but partially cured neat resin specimens were used for quasi-static testing. Tensile test specimens were partially pre-cured in a RTM molding tool at $60{ }^{\circ} \mathrm{C}$ for $6 \mathrm{~h}$. Compressive test specimens were cured in glass cylinders that were sealed on the bottom side with Tacky Tape and placed in a convection oven at a similar cure cycle. After cutting the tensile and the compressive specimens to the required dimensions, they were post-cured in convection oven at the temperatures and dwell times given in Table 1. The resulting graded glass transition temperatures were 
determined by DSC scans.

Fiber reinforced composite plates were manufactured by using a RTM mold with the dimensions of 500x500x2 $\mathrm{mm}^{2}$. Unidirectional carbon fiber PX35 fabrics from Zoltek with an areal weight of $333 \mathrm{~g} / \mathrm{m}^{2}$ were used as reinforcement material. Two different lay-ups were chosen: a unidirectional one [0 6 ] and a bidirectionally reinforced one $\left[45^{\circ} /-45^{\circ} / 45^{\circ}\right] \mathrm{S}$ resulting in a theoretical fiber volume content of $56 \%$. Specimens for bending experiments were cut to dimensions of $150 \times 15 \times 2 \mathrm{~mm}^{2}$ and post- cured by analogy to the neat resin samples.

Table 1. Post-cure cycles for partially cured tensile and compression specimens.

\begin{tabular}{llll}
\hline Post-cure temperature $\left({ }^{\circ} \mathrm{C}\right)$ & Dwell time $(\mathrm{h})$ & Resulting Tg tensile specimens $\left({ }^{\circ} \mathrm{C}\right)$ & Resulting Tg compressive specimens $\left({ }^{\circ} \mathrm{C}\right)$ \\
\hline 60 & 2 & 85 & 85 \\
\hline 80 & 2 & 93 & 97 \\
\hline 120 & 1 & 118 & 118 \\
\hline
\end{tabular}

\subsection{Thermo-analytical and Mechanical Test Methods}

DSC scans were conducted on a DSC1 Mettler Toledo with $40 \mu \mathrm{l} \mathrm{Al} \mathrm{crucibles} \mathrm{and} \mathrm{a} \mathrm{N2} \mathrm{purge} \mathrm{gas} \mathrm{rate} \mathrm{of} 40 \mathrm{ml} / \mathrm{min}$. DSC scans at different heating rates $(5 \mathrm{~K} / \mathrm{min}, 10 \mathrm{~K} / \mathrm{min}$ and $15 \mathrm{~K} / \mathrm{min}$ ) were performed in order to generate input data for reaction kinetic modelling in the software Netzsch Thermokinetics 3.1. Further DSC scans were done on partially cured samples at a heating rate of $10 \mathrm{~K} / \mathrm{min}$ in order to determine cure-dependent glass transition temperatures.

All quasi-static tests were performed on a Zwick Z 250. The tensile tests were performed with a $10 \mathrm{kN}$ load cell and a crosshead speed of $15 \mathrm{~mm} / \mathrm{min}$. The specimens had a cross-section of $4 \mathrm{~mm}$ x $2 \mathrm{~mm}$, a length of $100 \mathrm{~mm}$ and a gauge length was $50 \mathrm{~mm}$ (Fig. 2a). In order to cover the complete hardening behavior, the compressive tests were done with a $250 \mathrm{kN}$ load cell. A crosshead speed of $3 \mathrm{~mm} / \mathrm{min}$ was used. Cylindrical test specimens were cut to a diameter of $10 \mathrm{~mm}$ and a height of $10 \mathrm{~mm}$ and subsequently faced off in order to ensure plane parallel top surfaces (Fig. 2b). PTFE films were used to reduce friction between specimens and platens. The test temperatures were adjusted by a surrounding oven. The test specimens were introduced not earlier than 10 min prior to testing in order to prevent possible post-cure [10].

(a)

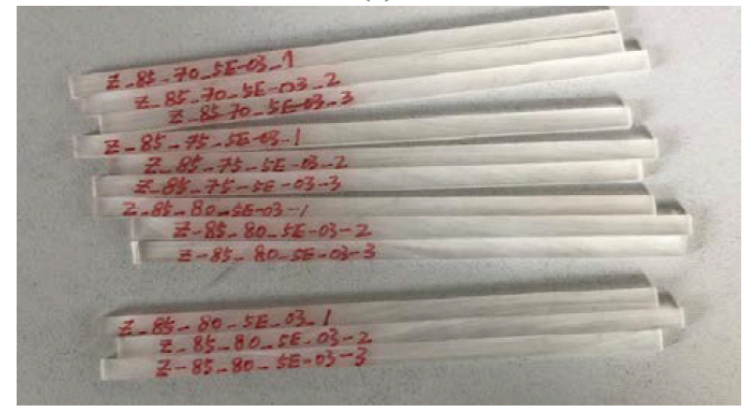

(b)

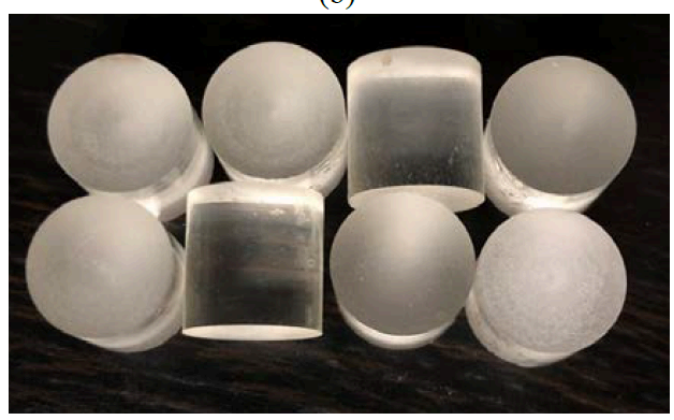

Fig. 2. Partially cured tensile and compressive test specimens. 
A self-made rotary draw bending device schematically depicted in Fig. 2 was used for the composite bending experiments. Exchangeable mold rolls allow adaption of the bending radius. Curvature can be varied by selecting the rotation angle. In order to generate elevated temperatures the draw bending device and the specimens are placed in a convection oven. Prior to the bending operations, the oven doors were opened. Hence, a slight temperature drop during deformation is possible.
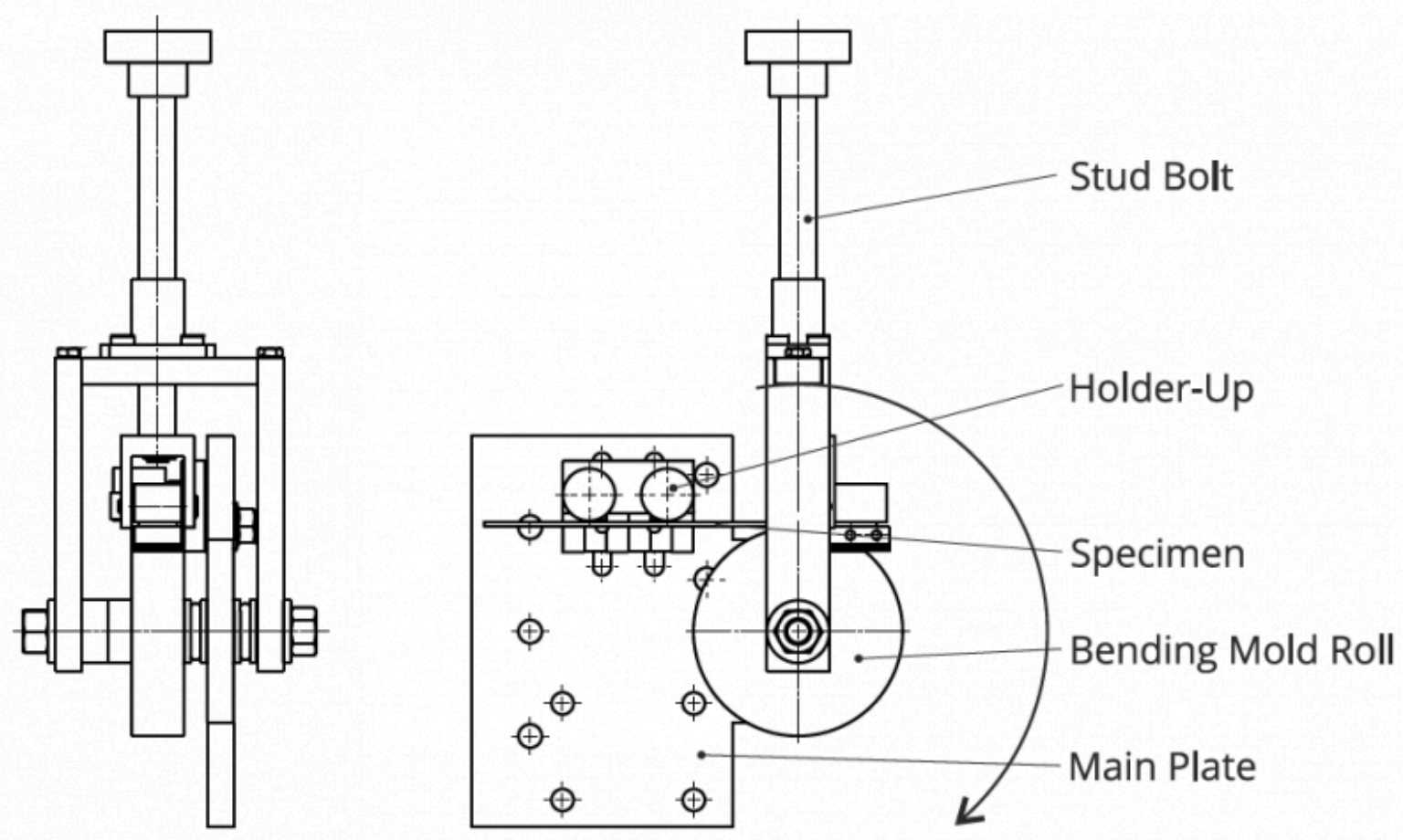

Fig. 3. Rotary draw bending device used for bending experiments

\section{Results}

\subsection{Reaction Kinetics and Cure-Dependent Glass Transition}

The exothermal heat flow data measured during DSC scans are used to develop a reaction kinetic model according to the methodology from [11]. The autocatalytic model

$$
\begin{aligned}
& \frac{d p}{d t}=k(1-p)^{n} \cdot p^{m} \quad \text { with } \\
& k=A \cdot e^{-\frac{E}{R T}}
\end{aligned}
$$

is chosen, containing four fitting parameters. E represents the activation energy, A is the pre-exponential factor, $\mathrm{n}$ is the reaction order and $\mathrm{m}$ is the autocatalytic constant. The universal gas constant $\mathrm{R}$ is a constant. Furthermore, cure-dependence of the glass transition temperature is described by the DiBenedetto equation: 


$$
T_{g}=T_{g 0}+\frac{\left(T_{g \infty 0}-T_{g 0}\right) \lambda p}{1-(1-\lambda) p}
$$

which comprises another three parameters. $T_{\mathrm{g} 0}$ is the initial glass transitions at $\mathrm{p}=0, T_{\mathrm{g}}$ is the ultimate glass transition at $\mathrm{p}=1$ and $\lambda$ represents the DiBenedetto constant. The results of the fitting operation are given in Table 2 .

Table 2. Parameters for the kinetic reaction model and the DiBenedetto equation

\begin{tabular}{lllllll}
\hline$E(\mathrm{~kJ} / \mathrm{mol})$ & $\log (A)\left(\mathrm{s}^{-1}\right)$ & $m(-)$ & $n(-)$ & $T_{g 0}\left({ }^{\circ} \mathrm{C}\right)$ & $T_{g \infty}\left({ }^{\circ} \mathrm{C}\right)$ & $\lambda(-)$ \\
\hline 53.1365 & 4.8482 & 0.3315 & 1.8938 & -50 & 120 & 0.4 \\
\hline
\end{tabular}

Depending on the heating rate the crosslinking reaction occurs between $60{ }^{\circ} \mathrm{C}$ and $250{ }^{\circ} \mathrm{C}$. Experimental and modelbased data are in good agreement (Fig. 4a). The glass transitions temperature can be described in good accordance with the experimental data by the DiBenedetto equation (Fig. 4b).

(a)

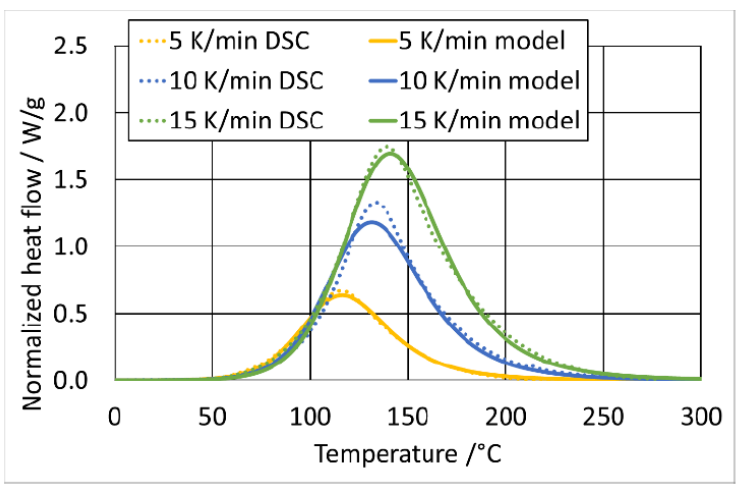

(b)

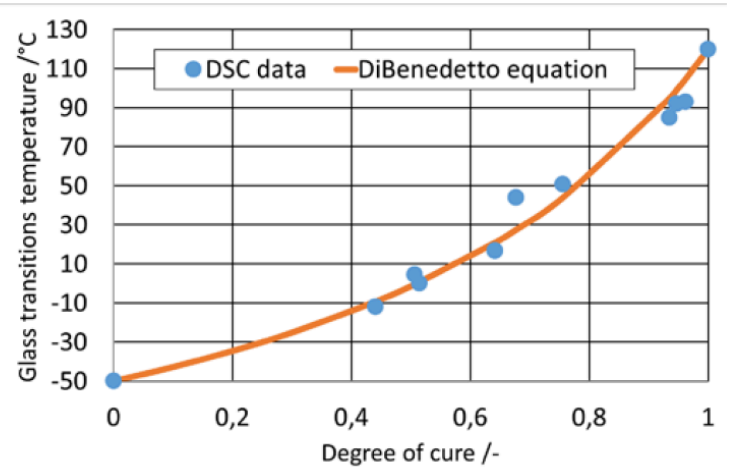

Fig. 4. Reaction behavior of the epoxy resin: (a) comparison of DSC data and model prediction, (b) cure-dependence of the glass transition

\subsection{Tensile and Compressive Tests}

The test temperatures used for quasi-static experiments were selected according to the determined glass transition temperatures. It is expected that the temperature difference $\left(T-T_{g}\right)$ dominates the plastic deformation behavior. For partially cured specimens $T_{g}$ will be not exceeded in order to prevent post-cure. Temperature between $20 \mathrm{~K}$ and $5 \mathrm{~K}$ below $T_{g}$ were selected. The fully cured specimens were subjected to an additional test $10 \mathrm{~K}$ above $T_{g}$. Three specimens were tested for each configuration.

Table 3. Test temperatures for the quasi-static tests 


\begin{tabular}{llll}
\hline$T_{g}$ tensile specimens $\left({ }^{\circ} \mathrm{C}\right)$ & Test temperatures tensile tests $\left({ }^{\circ} \mathrm{C}\right)$ & $T_{g}$ compressive specimens $\left({ }^{\circ} \mathrm{C}\right)$ & Test temperatures compressive tests $\left({ }^{\circ} \mathrm{C}\right)$ \\
\hline 85 & $65 ; 70 ; 75 ; 80$ & 85 & $65 ; 70 ; 75 ; 80$ \\
\hline 93 & $73 ; 78 ; 83 ; 88$ & 97 & $77 ; 82 ; 87 ; 92$ \\
\hline 118 & $98 ; 103 ; 108 ; 113 ; 128$ & 118 & $98 ; 103 ; 108 ; 113 ; 128$ \\
\hline
\end{tabular}

As no necking was observed, true strain und true stress data for tension denoted $\varepsilon^{t} \operatorname{tr}$ and $\sigma^{t}$ tr $\sigma$ as well as for compression denoted $\varepsilon^{c}$ tr and $\sigma^{c}$ tr were calculated according to eq. (4) to (7) using the measured values for crosshead displacement $\Delta l$ and force $F$ :

$$
\begin{aligned}
& \varepsilon_{t r}^{t}=\ln \left(1+\frac{\Delta l}{l_{0}}\right), \\
& \sigma_{t r}^{t}=\frac{F}{A_{0}}\left(1+\frac{\Delta l}{l_{0}}\right), \\
& \varepsilon_{t r}^{c}=-\ln \left(1-\frac{\Delta l}{l_{0}}\right), \\
& \sigma_{t r}^{c}=\frac{F}{A_{0}}\left(1-\frac{\Delta l}{l_{0}}\right) .
\end{aligned}
$$

In Fig. 5 (a-c) representative true stress-true strain curves of the performed tensile tests are shown. After an initially linear stress increase, which is associated with the elastic part of deformation, a maximum is reached followed by a drop of the measured stress values, which is probably related to intrinsic strain softening [12,13]. Both, the maximum and softening can be attributed to initiation of plastic flow. At low test temperatures, the resin shows higher stiffness and tends to brittle failure behavior. With increasing test temperatures, a transition from brittle to ductile behavior is observed. In this case, stress maximum and softening are followed by a rehardening. An increased DOC leads to a reduced modulus, yield stress and elongation at break. In Fig. 5 (d-f) the complementary true stress-true strain curves derived from compression tests are depicted. All specimens revealed a high degree of plasticity and ductile failure. The previously observed sequence of linear-elastic deformation, stress maximum, softening and rehardening is found again. Furthermore, the decrease in stiffness, yield stress and elongation at break with increasing DOC could be confirmed. Due to the lateral expansion of the specimens, maximum forces of more than $20 \mathrm{kN}$ were recorded. 
(a)

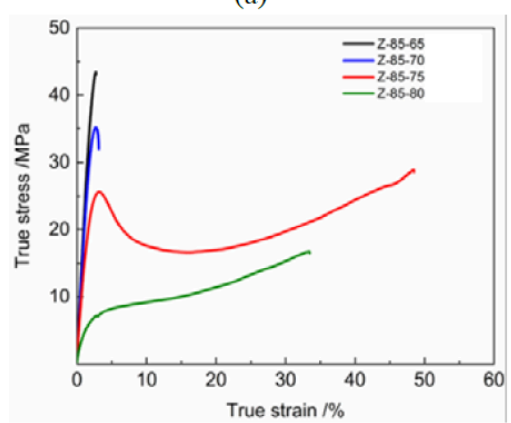

(d)

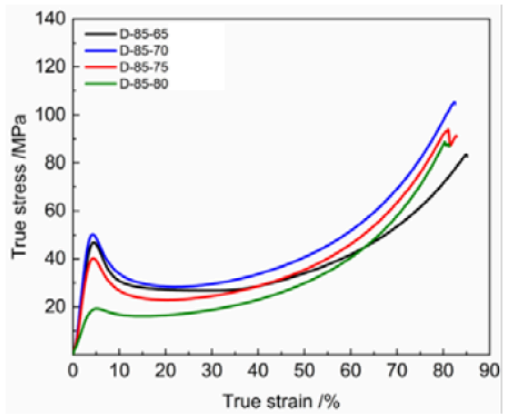

(b)

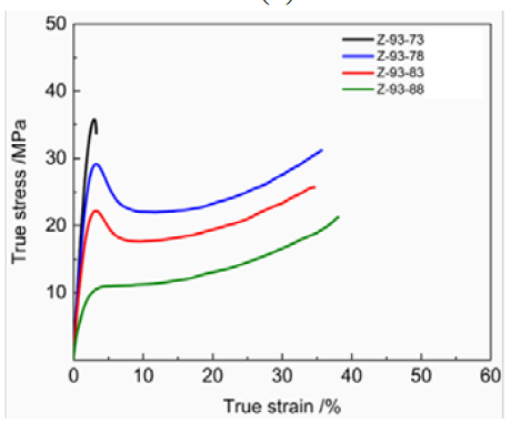

(e)

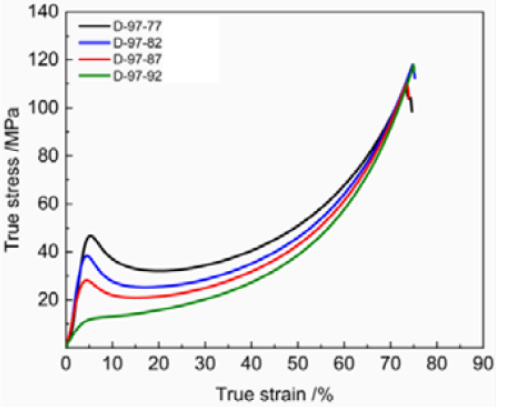

(c)

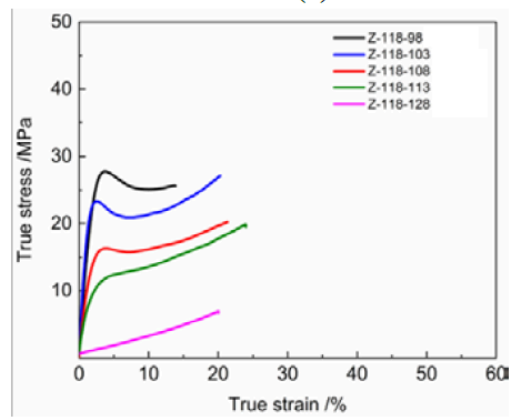

(f)

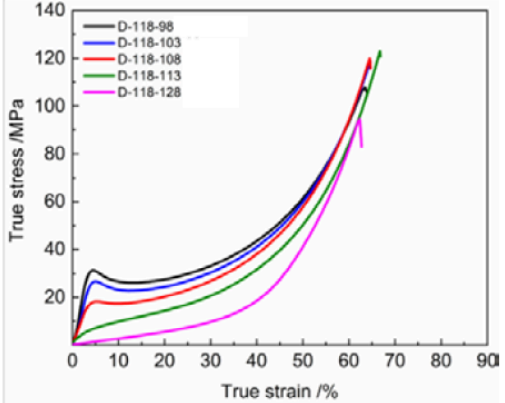

Fig. 5. Stress-strain curves determined in tensile and compressive tests at elevated temperatures using partially cured neat resin specimens

The elongation at break $\varepsilon_{b}$ is expected to be of major importance for the deformability of the fiber reinforced epoxy resin. Hence, in Fig. 6 the measured results for $\varepsilon_{b}$ are shown in dependence on $T_{g}$ and test temperature indicated by $\left(T-T_{\mathrm{g}}\right)$. It can be concluded that the lowest $T_{g}$ of $85^{\circ} \mathrm{C}$ is best suited to realize large plastic deformations. While in tension mode, a maximum $\varepsilon_{b}$ of $43 \%$ was reached $10 \mathrm{~K}$ below $T g$, in compression mode a maximum deformation of 90 $\%$ was possible when a test temperature $15 \mathrm{~K}$ below $T_{g}$ is used. With regard to temperature-induced post-cure during testing, it should be noted that a slight increase of $\mathrm{T}_{\mathrm{g}}$ is possible. Preliminary analyses conducted with a comparable resin system revealed a $T_{\mathrm{g}}$ increase of $6 \mathrm{~K}$ after $10 \mathrm{~min}$ exposure to a temperature $5 \mathrm{~K}$ below $T_{\mathrm{g}}$ [10]. $10 \mathrm{~K}$ below $T_{\mathrm{g}}$ its increase is limited to $2 \mathrm{~K}$ in $10 \mathrm{~min}$.

(a)

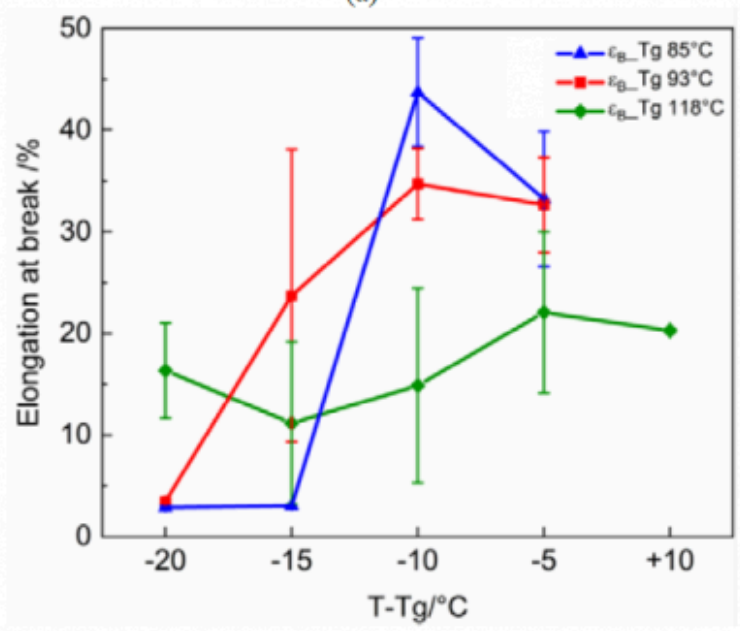

(b)

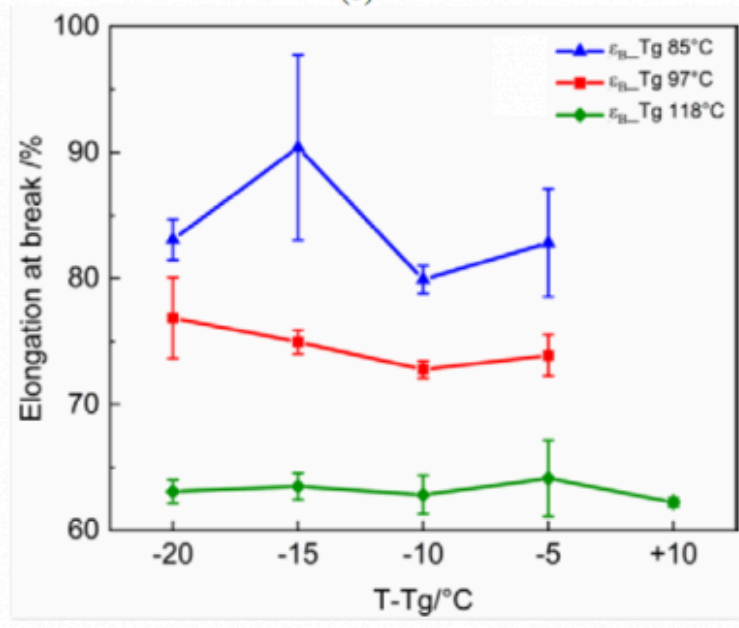


Fig. 6. Elongations at break determined in (a) tensile and (b) compressive tests in dependence on temperature and DOC

\subsection{Bending Tests on Composite Specimens}

The gathered knowledge from thermo-analytical and mechanical neat resin characterization was subsequently transferred to bending experiments on CFRP specimens. Table 4 compares the varied parameters with the results. Roll diameters of $32 \mathrm{~mm}$ and $48 \mathrm{~mm}$ were selected. Partially cured composite material with a $T_{\mathrm{g}}$ of $93{ }^{\circ} \mathrm{C}$ was chosen for both lay-ups. The test temperatures were determined iteratively starting with the most promising temperatures found during neat resin characterization. The initial bend angle was adjusted manually by rotating the stud bolt. After expiration of a defined dwell time at the initial bend angle, the specimen was unloaded, removed and measured. The results are presented by evaluating the final bend angle after unloading and the occurrence of damage patterns like fiber kinking, wrinkling or resin cracks (Table 4).

The specimens with $\pm 45^{\circ}$-reinforcement showed overall good formability. Both tested temperatures of $80^{\circ} \mathrm{C}$ and $90{ }^{\circ} \mathrm{C}$ resulted in predominantly plastic deformation. An initial bend angle of $90^{\circ}$ and a roll diameter of $48 \mathrm{~mm}$ yielded a final bend angle between $84^{\circ}$ and $88^{\circ}$. No visible damages occurred (Fig. 7a). An increase dwell time from 10 min to 30 min slightly improved the results.

Table 4. Parameters and results of the rotary draw bending experiments on composite specimens

\begin{tabular}{llllllll}
\hline Lay-up & Tg & $\begin{array}{l}\text { Test temperature } \\
\left({ }^{\circ} \mathrm{C}\right)\end{array}$ & $\begin{array}{l}\text { Roll diameter } \\
(\mathrm{mm})\end{array}$ & $\begin{array}{l}\text { Dwell time } \\
(\mathrm{min})\end{array}$ & $\begin{array}{l}\text { Initial bend angle } \\
\left({ }^{\circ}\right)\end{array}$ & $\begin{array}{l}\text { Final bend angle } \\
\left({ }^{\circ}\right)\end{array}$ & $\begin{array}{l}\text { Damage } \\
\text { occurred? }\end{array}$ \\
\hline$\left[45^{\circ} /-45^{\circ} / 45^{\circ}\right] \mathrm{S}$ & 93 & 80 & 32 & 10 & 90 & 84,5 & No \\
\hline$\left[45^{\circ} /-45^{\circ} / 45^{\circ}\right] \mathrm{S}$ & 93 & 90 & 32 & 10 & 90 & 87,5 & No \\
\hline$\left[45^{\circ} /-45^{\circ} / 45^{\circ}\right] \mathrm{S}$ & 93 & 80 & 32 & 30 & 90 & Yes \\
\hline$\left[0^{\circ} 6\right]$ & 93 & 90 & 48 & 30 & 60 & - & Yes \\
\hline$\left[0^{\circ} 6\right]$ & 93 & 120 & 48 & 30 & 60 & 18 & No \\
\hline$\left[0^{\circ} 6\right]$ & 93 & 140 & 48 & 30 & 60 & & \\
\hline
\end{tabular}

In contrast to the $\pm 45^{\circ}$-specimens, the material with $0^{\circ}$-reinforcement revealed rather elastic behavior leading to notable spring back after unloading. The previously used parameters were not suitable to avoid failure. To solve this problem, a reduced initial bend angle of $60^{\circ}$ and a roll diameter of $48 \mathrm{~mm}$ were chosen. The specimens tested at 90 ${ }^{\circ} \mathrm{C}$ and $120^{\circ} \mathrm{C}$ still showed fiber wrinkles and matrix failure on compression side (Fig. 7b). At a further increased test temperature of $140{ }^{\circ} \mathrm{C}$, damage could be avoided, while the amount spring back remained comparatively high. A final bend angle of $18^{\circ}$ could be reached. 
(a)

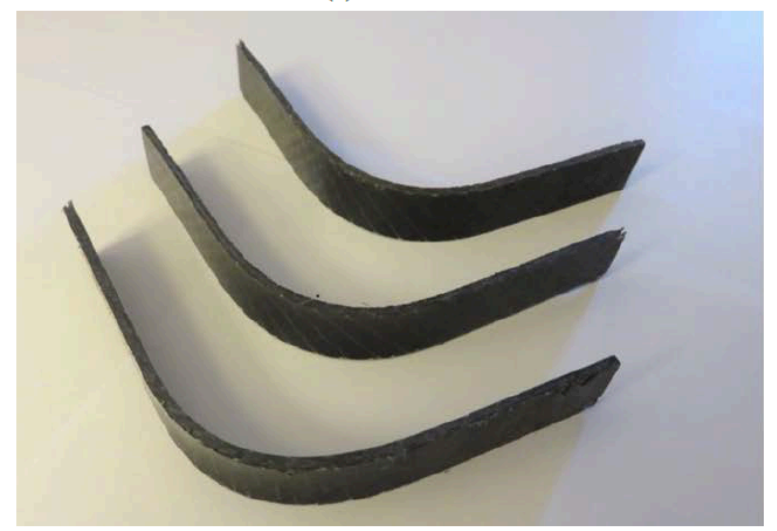

(b)

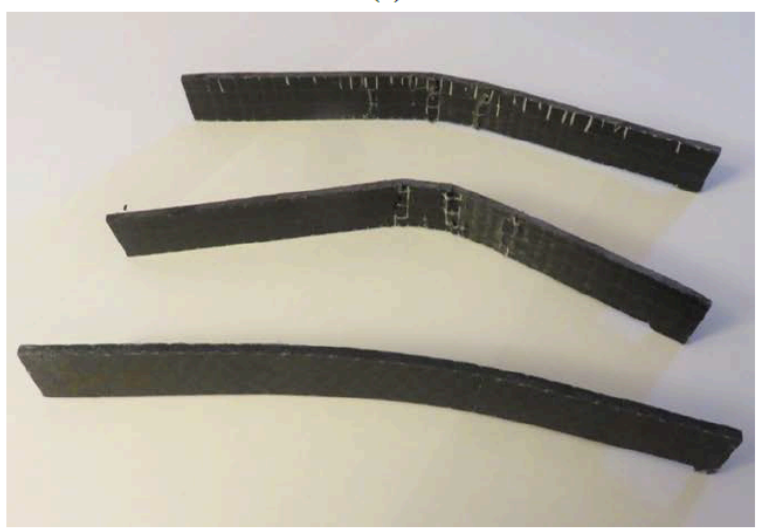

Fig. 7. Exemplary results of the bending experiments on CFRP composite specimens with (a) $\pm 45^{\circ}$ and (b) $0^{\circ}$ reinformcement

\section{Conclusion}

Sustainable buildings and resource-efficient manufacturing processes represent essential challenges for future construction industry and architecture. In this context, novel rebars based on high-performance materials like CFRP are subject to current research efforts aiming at improved durability, increased design freedom and lightweight design.

In order to contribute to the required development of flexible and economic manufacturing methods, this work suggests introduction of secondary forming of thermoset-based CFRP rebars as a novel process. For this purpose, a commercially available epoxy resin system was selected and thoroughly characterized. Based on the assumption, that partial cure and elevated temperatures enable a notable increase in plasticity, a characterization program comprising thermo-analytical and mechanical tests was designed. DSC scans were used to develop a reaction kinetic model and to derive adapted cure cycles resulting in partially cured specimens. Neat resin specimens were prepared and used for quasi-static tensile and compressive tests at elevated temperatures. It was found that formability increases significantly when the glass transitions temperature is approached. In addition, a reduced degree of cure has a beneficial effect on plastic deformation potential. Crossing the Tg does not further increase the elongation at break of the neat resin. The gathered knowledge was transferred to bending experiments on CFRP stripes. Specimens with a reinforcement diagonal to the bending axes showed a high degree of plasticity and were unsusceptible to damage when deformed $10 \mathrm{~K}$ below and at $\mathrm{Tg}$. Using a rotary draw bending device with a roll diameter of $32 \mathrm{~mm}$, bend angles close to $90^{\circ}$ were reproducibly realized. In contrast, specimens with a rebar-like reinforcement in $0^{\circ}$-direction were much more challenging to bend as they reveal fiber-dominated behavior. After some iterations, a temperature increase wide above $\mathrm{Tg}$ allowed a deformation to a bend angle of $18^{\circ}$ without causing any damage.

Regarding these results, the feasibility of the initially envisaged functionalization of CFRP rebars by secondary forming require a nuanced assessment. On the one hand, the realization of structures with small bend angles like stirrups seems to remain difficult. On the other hand, a slight bending of CFRP rebars for use in shell constructions (cf. Fig. 1) appears to be indeed possible.

Further research is required to confirm the presented results. For this purpose, it is planned to perform bending experiments on rebars with circular cross section in order to further define the process window for secondary forming of thermoset based CFRP. 


\section{Acknowledgements}

This research was funded by the Federal Ministry of Education and Research (project V4.16) within the Carbon Concrete Composites (C3).

\section{Bibliography}

[1] Ilg P, Hoehne C, Guenther E. High-performance materials in infrastructure: a review of applied life cycle costing and its drivers - the case of fiber-reinforced composites. Journal of Cleaner Production 2016;112:926-45. https://doi.org/ 10.1016/j.jclepro.2015.07.051.

[2] Böhm R, Thieme M, Wohlfahrt D, Wolz D, Richter B, Jäger H. Reinforcement Systems for Carbon Concrete Composites Based on Low-Cost Carbon Fibers. Fibers 2018;6(3):56. https://doi.org/10.3390/fib6030056.

[3] Jansen K. Mass production of curved profiles for car bodies - Process and machines. In: N.N., editor. SPE ACCE Conference. SPE Automotive and Composites Divisions; 2001.

[4] N.N. Schöck Combar; Available from: https://www.schoeck.co.uk/view/5470/ Technical_Information_Schoeck_Combar_international\%5B5470\%5D.pdf.

[5] Mayr AE, Cook WD, Edward GH. Yielding behaviour in model epoxy thermosets - I. Effect of strain rate and composition. Polymer 1998;39(16):3719-24. https://doi.org/10.1016/S0032-3861(97)10334-2.

[6] Cook WD, Mayr AE, Edward GH. Yielding behaviour in model epoxy thermosets - II. Temperature dependence. Polymer 1998;39(16):3725-33. https://doi.org/10.1016/S0032-3861(97)10335-4.

[7] Crawford ED, Lesser AJ. Brittle to ductile: Fracture toughness mapping on controlled epoxy networks. Polym. Eng. Sci. 1999;39(2):385-92. https://doi.org/10.1002/pen.11425.

[8] Yakacki CM, Willis S, Luders C, Gall K. Deformation Limits in Shape-Memory Polymers. Adv. Eng. Mater. 2008;10(1-2):112-9. https://doi.org/10.1002/adem.200700184.

[9] Detwiler AT, Lesser AJ. Characterization of double network epoxies with tunable compositions. J Mater Sci 2012;47(8):3493-503. https://doi.org/10.1007/s10853- 011-6182-4.

[10] Opfermann J. Kinetic Analysis Using Multivariate Non-linear Regression. I. Basic concepts. Journal of Thermal Analysis and Calorimetry 2000;60(2):641-58. https://doi.org/10.1023/A:1010167626551.

[11] van Melick HGH, Govaert LE, Meijer HEH. On the origin of strain hardening in glassy polymers. Polymer 2003;44(8):2493-502. https://doi.org/10.1016/S0032- 3861(03)00112-5.

[12] Kontou E. Viscoplastic deformation of an epoxy resin at elevated temperatures. J. Appl. Polym. Sci. 2006;101(3):2027-33. https://doi.org/10.1002/app.23768.

[13] Müller M, Winkler A, Gude M, Jäger H. Aspects of reproducibility and stability for partial cure of epoxy matrix resin. J. Appl. Polym. Sci. 2020;137(5):48342. https://doi.org/10.1002/app.48342.

PDF automatically generated on 2021-05-20 17:24:18

Article url: https://popups.uliege.be/esaform21/index.php?id=4252

published by ULiège Library in Open Access under the terms and conditions of the CC-BY License 
ESAFORM 2021. MS02 (Composite), 10.25518/esaform21.4252

(https://creativecommons.org/licenses/by/4.0) 